\title{
E a corrupção coube em 20 centavos
}

\author{
Cristina Teixeira Vieira de Melo' \\ Paulo Roberto Givaldi Vaz" \\ I - UFPE \\ Recife (PE), Brasil \\ II - UFRJ \\ Rio de Janeiro (RJ), Brasil
}

Resumo: Voltamos às jornadas de junho de 2013 para estudar como o discurso de combate à corrupção tornou-se pauta de manifestações que, de início, visavam a revogar o aumento das tarifas de ônibus. Mostramos a relevância da violência policial na generalização da condição de vítima, possibilitando o deslocamento posterior para a de cidadãos vítimas de um Estado imoral e corrupto. Apontamos o intervalo entre os dias 13 e 17 como o momento em que houve intensas movimentações da mídia hegemônica e de grupos com respaldo nas redes sociais para introduzir a corrupção na pauta das manifestações.

Palavras-chave: Jornadas de junho; violência policial; corrupção; vítima.

Abstract: We returned to the "Jornadas de Junho de 2013"[Days of June 2013] to study how the anti-corruption discourse became part of the agenda of demonstrations that, initially, aimed only at repealing an increase in bus fares. We show the relevance of police violence in the generalization of the claim to victim status . This generalization allowed a subsequent generalization: that of citizens who are victims of an immoral and corrupt state. We point out the interval between the 13th and 17th as the moment in which there were intense movements of the hegemonic media and of groups backed by the social networks to introduce the corruption in the agenda of the manifestations.

Keywords: Days of June; police violence; corruption; victim.

“Peraí... Em três semanas dá para diminuir o índice de aprovação de 57\% para 30\%?

[...] Esse negócio de ir pra rua tem um poder muito grande!

Para mudar o cenário atual, portanto, a rua pode ser um caminho.

Vamos levar as pessoas para a rua!

Mas temos que ser rápidos".

(Rogerio Chequer, líder do Movimento Brasil Livre) 


\section{As jornadas de junho e a disputa de sentido}

Quando as manifestações de junho de 2013 tomaram as ruas do Brasil, todos se perguntavam "O que está ocorrendo?", "O que querem os manifestantes?", "O que tudo isso significa?". Ninguém sabia ao certo explicar o que era o movimento, quem o representava, de que forma se organizava, para onde ele ia. Algo escapava e permanecia à deriva das racionalidades instituídas.

Contornemos diferentes dimensões dessa deriva. De início, há a surpresa. O Movimento Passe Livre (MPL) não esperava que a luta contra o aumento da passagem de ônibus por 20 centavos durasse quase um mês, levasse às ruas cerca de 13 milhões de indivíduos e ocorresse em centenas de cidades. As mobilizações anteriores, como a Revolta do Buzu e a Revolta da Catraca, tinham como atores principais estudantes secundaristas, endereçavam suas reivindicações a prefeituras e suas manifestações jamais ultrapassaram o número de 10 mil participantes. Já em relação às condições sociais, embora tenha havido uma gama variada de insatisfações que se expressaram ao longo das jornadas, as pesquisas de opinião ainda não tinham sido capazes de apreendê-las. Em março de 2013, o governo Dilma era aprovado (ótimo e bom) por 79\% da população. Por fim, a trajetória da economia ainda foi ascendente em 2103, embora com redução do ritmo de crescimento.

Parte do desafio reside na velocidade com que o movimento ganhou força e amplitude, aumentando o número de participantes e de cidades envolvidas: a primeira manifestação ocorreu no dia 6 de junho, na cidade de São Paulo, e contou com cerca de 2 mil pessoas; em 13 de junho, no quarto ato, houve manifestações fortemente reprimidas pela polícia nas cidades do Rio de Janeiro e de São Paulo, ambas com pouco mais de 20 mil manifestantes; no dia 20, duas semanas desde o primeiro protesto, em atos já não mais convocados pelo $\mathrm{MPL}$, que iniciara a luta contra o aumento das passagens de ônibus, ocorreram manifestações em mais de cem cidades por todo o país, sendo que ao menos em 4 capitais os atos contaram com mais de 100 mil pessoas. Em duas semanas, portanto, o total de manifestantes foi multiplicado por mil, pois mais de 2 milhões foram às ruas no dia 20.

Para realçar a surpresa causada pela velocidade, consideremos um movimento com dinâmica lenta de acumulação de forças e que visava a um embate final decisivo: a campanha das Diretas Já. O lançamento nacional, feito por um comitê reunindo partidos e entidades da sociedade civil, foi um comício realizado em 12 de janeiro de 1984, na cidade de Curitiba; no dia 25 do mesmo mês, no aniversário da cidade de São Paulo, um grande ato reuniu entre 250 e 400 mil pessoas. A partir daí a campanha ganhou momento, com atos se sucedendo em diferentes capitais, preferencialmente na forma de comícios em que falavam políticos da oposição à ditadura militar, personalidades da sociedade civil e artistas. Os dois últimos ocorreram em abril, nas duas semanas 
anteriores à votação pelo Congresso da emenda estabelecendo as eleições diretas: um comício no dia 10 na cidade do Rio de Janeiro, que reuniu mais de 1 milhão de pessoas, e uma passeata na cidade de São Paulo na semana seguinte que contou com mais de 1 milhão e 500 mil manifestantes.

Três meses, em vez de 2 semanas; convocação central por um comitê suprapartidário, em vez de convocação difusa tornada possível pela existência das redes sociais; dinâmica de acumulação de forças tendo em vista uma batalha final, em vez de dinâmica explosiva, sem objetivo final claro (a maior manifestação das jornadas, no dia 20, aconteceu quando o aumento de passagens tinha sido revogado nas cidades do Rio de Janeiro e de São Paulo); atos em que poucos indivíduos célebres se exprimem para audiência de muitos, em vez de todos poderem se expressar, sem hierarquia clara e prévia entre os manifestantes.

Há uma última diferença: ao invés de sentido uniforme ao longo do tempo pela existência de uma reivindicação única, nas jornadas houve disputa sobre o sentido tanto ao longo do movimento, quanto após seu esvaziamento.

Para ilustrar esses sentidos em disputa, comparemos o livro Vinte centavos: a luta contra o aumento, publicado pelos integrantes do MPL, com o de autoria das organizações O Globo, O Brasil nas ruas. O primeiro abrange o período de 6 de junho, dia da primeira passeata em São Paulo, a 19 de junho, data em que a redução da tarifa foi anunciada. O segundo relata os fatos de 18 de junho, quando "o movimento ganha uma cara nacional", ao final do mês, 30 de junho. Ou seja, uma narrativa principia justo quando a outra termina. A decisão do MPL de finalizar o seu relato no dia 19 de junho deixa de fora do debate o momento em que as manifestações se massificam, se nacionalizam e as reivindicações se ampliam, fatores apontados como facilitadores do sequestro da pauta pela direita. Por sua vez, O Globo subtrai a cobertura negativa que fez do movimento no período anterior ao dia 18 de junho, impedindo o leitor de perceber que num curto intervalo de tempo ele "virou a casaca", assim como o fez toda a mídia corporativa. Essas duas narrativas refletem claramente posicionamentos à esquerda e à direita sobre as jornadas de junho.

As jornadas de junho desdobraram diversos sentidos à medida que iam ocorrendo: o direito à cidade, o direito de protestar, a defesa radical da democracia, a demanda por serviços públicos de qualidade. Todos esses sentidos são marcadamente libertários. Contudo, um outro sentido, em conflito potencial com os primeiros, emergiu: o combate à corrupção. Mas, para quem acredita que a corrupção é causa maior dos males da sociedade brasileira, não há conflito entre essas diversas demandas. Ao crescer, as mobilizações não poderiam ficar limitadas à denúncia dos efeitos; deveriam, sim, mesmo que tateando, se endereçar à causa.

Por ora, basta ter como signo do potencial de conflito entre a denúncia de corrupção e as reivindicações iniciais das jornadas a fala de Arnaldo Jabor no Jornal da Globo de 12 de junho, censurando o MPL por causar tanta "depredação" por meros 20 centavos, e afirmando que o melhor seria uma mobilização por algo realmente relevante, 
como o combate à emenda constitucional que atribuía apenas à Polícia Federal o poder de investigação, a PEC37. Também é significativa a afirmação de Pablo Ortellado, integrante do MPL, de que quando as manifestações aumentaram exponencialmente e o combate a corrupção entrou na pauta, houve a "incapacidade de encontrar um horizonte ideológico comum" (JUDENSNAIDER et al, 2013, p. 235).

Eis a razão de frisarmos a entrada da corrupção na pauta de reivindicações das jornadas: este texto busca sua singularidade por meio da construção de distâncias com duas análises das jornadas de junho de 2013 de ampla repercussão na academia e na esfera pública, a de Leonardo Avritzer (2016), em seu livro Impasses da democracia no Brasil, e a de Jessé de Souza (2016), em A Radiografia do Golpe. Ambas mostram que as jornadas começaram como mobilização promovida por grupos à esquerda do PT; frisam que, a partir dos dias 17 e 20 de junho, houve uma inflexão conservadora marcada pelo crescimento da participação da classe média, pela crítica aos partidos e pela bandeira da anticorrupção; por fim, argumentam que essa inflexão conservadora constituiu a base a partir da qual foram feitas as mobilizações de 2015 e 2016 de luta contra a corrupção e que serviram de legitimação "popular" para o impeachment de Dilma Rousseff. Partilhamos esses três pontos.

A base empírica da análise de Avritzer é constituída por dados sobre temas-chave nas redes sociais ao longo da jornada; como teórico da luta contra a anticorrupção numa perspectiva republicana, seu princípio básico é o de que a luta contra a corrupção é essencial para a vitalidade da democracia no Brasil. Suas críticas aos movimentos conservadores se concentram, assim, na seletividade das denúncias e na forma do combate, que não ataca as estruturas que tornam possível a corrupção (presidencialismo de coalizão, financiamento privado das campanhas e ausência de controle social sobre obras).

Já Souza baseou seus argumentos na cobertura da jornada pelo Jornal Nacional da Rede Globo. Sua análise enfatiza como o discurso moralista pode ser atraente para a classe média e propõe que a atratividade independe de mudanças recentes no conceito de corrupção, supondo uma espécie de constância do uso político da denúncia de imoralidade contra governos populares na história da República no Brasil.

Em termos teóricos, a distância com o argumento de Avritzer é nossa aposta de que a defesa da democracia não se limita ao combate contra a corrupção; requer ainda que se questione os movimentos de anticorrupção, esses "guerreiros da integridade" ${ }^{1}$, pelos efeitos deletérios que causam na própria democracia, efeitos que ora testemunhamos: crise da política pela judicialização e midiatização e redução do Estado de Direito pela necessidade de punir com rigor esse tipo contemporâneo de monstro, os "políticos".

1 Esse é o subtítulo de uma coletânea européia que analisa os movimentos de anticorrupção na Europa e Austrália (SOUZA; LARMOUR; HINDESS, 2009). Uma pesquisa realizada em outubro de 2017 no Scielo, buscando artigos com o termo "corrupção" no título ou em palavras-chave, encontrou 42 textos. Com a exceção de um, todos tinham como objetivo determinar as causas e consequências da corrupção. A exceção não era texto de autor brasileiro; tratava-se de artigo escrito por uma autora portuguesa que discutia os efeitos negativos para a democracia da luta anticorrupção. 
Em relação aos argumentos de Souza, enfatizamos as mudanças recentes no conceito que tornam a luta anticorrupção um potente mecanismo de legitimação do capitalismo e que facilitam as estratégias da classe média de racionalização do desconforto com medidas de redução de desigualdade, isto é, ao invés de uma continuidade no uso das denúncias de corrupção na história de nossa República, frisamos uma mudança histórica no conceito e nas denúncias que ele então autoriza.

Em relação à base empírica, o diferencial é que nosso corpus consiste de notícias publicadas na assim chamada grande imprensa. Por não termos centrado o argumento apenas no momento inicial das jornadas (entre 6 e 10 de junho) e naquele em que se marca a mudança (entre 17 e 20 de junho), foi possível apreender tanto a relevância da violência policial contra os manifestantes na generalização da crítica ao Estado, quanto a sugestiva convergência, temporal e temática, de mudança na cobertura pelos diferentes veículos da mídia impressa hegemônica.

A singularidade do posicionamento implica, então, considerar surpreendente o fato de a corrupção ter se tornado o elemento com maior dinamismo das reivindicações e o sentido que produziu futuro. Daí a questão: como a corrupção coube numa mobilização que lutava contra o aumento de passagem? Essa questão pode ser desdobrada em duas perguntas. A primeira: como o discurso de combate à corrupção permitiu uma crítica do Estado que fez sentido com um conjunto de críticas já presentes nos meios de comunicação e nas redes sociais, especialmente os gastos com a Copa do Mundo e as Olimpíadas, ao mesmo tempo que permitia racionalizar uma série de insatisfações com as medidas de inclusão social promovidas pelos governos do PT? A segunda pergunta está centrada nas representações da mídia corporativa e visa a determinar as estratégias retóricas que tornaram possível transformar a revolta contra a violência policial nas primeiras manifestações, especialmente a do dia 13 de junho nas cidades de São Paulo e Rio de Janeiro, em crítica generalizada do Estado, tendo a corrupção como foco da indignação.

Tendo em vista nosso interesse nas estratégias que a mídia hegemônica impressa adotou ao longo da cobertura das jornadas de junho, elegemos como objeto prioritário de análise as notícias divulgadas pelo O Estado de São Paulo (OESP), Folha de São Paulo (FSP), O Globo e Veja no intervalo de 6 de junho, data de início das manifestações, até 31 de outubro de 2013, quando o formato dos protestos muda para o das ocupações. Em função dessa larga abrangência temporal e da quantidade de veículos investigados, nosso corpus de pesquisa compreende mais de uma centena de editoriais, colunas, notícias, reportagens, notas e fotografias, mas em virtude do espaço limitado deste artigo, trazemos para análise apenas os exemplos que melhor explicitam as diferentes fases da jornada e as razões para as transições de fase.

\section{O combate à corrupção e as insatisfações da classe média}

Duas mudanças recentes no conceito de corrupção permitem compreender como sua crítica pode ter sub-repticiamente entrado como reivindicação das jornadas. A primeira 
concerne ao estatuto da corrupção como objeto de conhecimento. Até a década de 1990, pensava-se que cada caso de corrupção era diferente, sendo impossível a generalização e ainda mais a quantificação; por só admitir, então, conhecimento local de casos, sempre contextualizado, o objeto "corrupção" era estudado pela antropologia, sociologia e ciência política (KRASTEV, 2004, p. 4). Em meados dos anos 1990, porém, surgem e se disseminam índices comparando quantitativamente países segundo seu nível de corrupção, o mais conhecido sendo o criado pela ONG (organização não governamental) Transparência Internacional. Se a quantificação é possível, a esperada correlação entre nível de corrupção e subdesenvolvimento é transformada em relação de causalidade, com altos níveis de corrupção explicando subdesenvolvimento, pobreza e desigualdade.

O discurso de combate à corrupção é uma forma poderosa de legitimação do capitalismo. Quando se pergunta hoje por que um país é subdesenvolvido, por que não tem serviços públicos de qualidade e por que há tanta desigualdade, há uma resposta pronta, bastante difundida, que em nada questiona o funcionamento do capitalismo: só aponta como causa a imoralidade e incompetência de políticos e funcionários. Legitimação tão mais poderosa pelo fato de ter como "solução" a redução ou extinção de qualquer limite ao livre fluxo de capitais e mercadorias.

Uma segunda mudança no conceito de corrupção, consolidada em meados da década de 1990 e também associada à ascensão do neoliberalismo, concerne ao foco da indignação. O código penal brasileiro, redigido ainda na década de 1940, diferencia entre o crime de corrupção ativa (quem corrompe) e de corrupção passiva (quem é corrompido). Pela diferença de valor que a linguagem cotidiana marca entre ativo e passivo, percebe-se que a ênfase da indignação estava outrora focada em quem corrompia. A ênfase hoje recai sobre quem é corrompido, como na definição proposta pelo Banco Mundial em 1997: corrupção é abuso de cargo público para benefício privado. O Ministro do Supremo Tribunal Federal Luís Roberto Barroso (2018, p. 31) secunda o Banco Mundial ao propor que "corrupção significa levar vantagem indevida para fazer ou deixar de fazer alguma coisa". Afinal, só quem tem cargo público tem poder discricionário para favorecer indivíduos e empresas.

A mudança no objeto privilegiado de indignação moral resulta, de fato, de uma continuidade: as democracias contemporâneas mantêm a crença na política como forma de construir o futuro através da ação coletiva. Essa crença, antes, se dava como possibilidade de compreender o nexo entre os problemas sociais do presente e as características da sociedade, de modo a agir coletivamente sobre elas para reduzir ou extinguir os sofrimentos que causavam.

Hoje, porém, com o desaparecimento da utopia comunista e com o capitalismo aparecendo como o horizonte incontornável de ordenação das relações de trabalho, acreditar que a imoralidade dos políticos é causa maior de inúmeros sofrimentos implica ainda em ter a esperança de que é possível agir para reduzi-los ou minorá-los. Para todo aquele que adere à crença de que a corrupção é causa maior de inúmeros sofrimentos, 
a transparência do Estado aos cidadãos parece a utopia apropriada a nossa era (ROSANVALLON, 2006, p. 262). Se a imoralidade atual ou virtual de políticos e funcionários é controlada pela visibilidade de suas ações, a economia cresce, os serviços públicos melhoram, a insegurança é minorada, a desigualdade tende a se identificar à que deveria existir pelo mérito e uma série de eventos trágicos, como acidentes e catástrofes, deixa de ocorrer.

Esse leque de crenças sobre os nexos entre corrupção, Estado e sociedade constituiu a tela em que a classe média projetou seu incômodo com as políticas de redução de desigualdades promovidas pelos governos do PT. O fato de não ter havido maiores mobilizações contra a corrupção após o golpe parlamentar que depôs o Governo Dilma é sintoma de que outros descontentamentos estimulavam os manifestantes de classe média em 2013 e, sobretudo, em 2015 e 2016. Listamos abaixo alguns deles.

A aprovação da PEC das domésticas, em abril de 2013, dificultou o acesso da classe média à uma mão de obra de baixo custo que reduzia substancialmente seus cuidados com a casa. Também foi em 2013 que o Congresso aprovou uma ementa que destinou $50 \%$ das vagas de Universidades Federais para cotistas e alunos de escolas públicas. Já no plano simbólico, muitos não gostavam de ver os pobres circulando em áreas que antes eram prioridade dos ricos, como aeroportos, shopping centers e bairros nobres. A indignação com o espaço que os mais pobres estavam conquistando chegou à escola. O livro Por uma vida melhor, aprovado no Programa Nacional do Livro Didático de 2011, ao abordar a questão da variação linguística, foi acusado de estar fazendo a apologia do "erro" de português e desvalorizar o domínio da norma culta.

O discurso contemporâneo de combate à corrupção pôde condensar todas essas insatisfações, deslocando-as de um alvo que ainda é considerado ilegítimo - condenar a ascensão social de muitos em um país de distribuição de renda tão desigual - para o alvo hoje sumamente legítimo do combate à imoralidade na política. A inquietação com a redução de desigualdades foi racionalizada como apelo à moralidade. O lugar de guerreiro da integridade permitiu à classe média acreditar que se posicionava contra o governo do PT porque lutava pelo bem comum e não porque estivesse incomodada com a perda de privilégios materiais e simbólicos.

\section{As fases das jornadas e seus atores sociais}

Propomos uma divisão das jornadas de junho em quatro grandes fases: a primeira engloba o período de 6 a 13 de junho, quando o movimento surge; a segunda, de 14 a 16 de junho, quando ele sofre uma inflexão e começa a ganhar novo desenho; a terceira, de 17 a 20, quando ele se amplia e se diversifica; e a quarta, do dia 21 de junho em diante, quando ele vai perdendo força. Voltamos especial atenção à passagem da segunda para a terceira fase, pois é aí que se dá uma mudança drástica não apenas no movimento em si, mas também no tratamento dado pela mídia hegemônica aos atores nele envolvidos. 
Durante a primeira fase ocorrem, em São Paulo, atos nos dias 6, 7, 11 e 13 de junho. As passeatas desse período são convocadas pelo MPL contra o aumento de 20 centavos na tarifa de ônibus, mobilizam um número menor de pessoas, são alvo de forte repressão policial e têm cobertura negativa da mídia.

Na segunda fase, de 14 a 16 de junho, não há protestos de rua em São Paulo. No entanto, é intensa a articulação nas redes sociais condenando a violência policial sofrida pelos manifestantes, reivindicando o direito que todos têm de protestar e apoiando o movimento. Atenta ao discurso nas redes sociais, a mídia prevê o agigantamento das manifestações e muda o tipo de cobertura, no lugar de desqualificar os manifestantes como "perturbadores da ordem", passa a enquadrá-los como vítimas da ação policial. Já nesse momento aparece na mídia a insinuação de que a corrupção configuraria uma das insatisfações dos manifestantes. No entanto, o combate à corrupção não era tema de destaque nas passeatas até então.

Na terceira fase, de 17 a 20 de junho, os protestos se nacionalizam, há um aumento gigantesco do número de manifestantes nas ruas, as pautas se ampliam (tarifa, violência policial, corrupção, PEC 37, cura gay, Copa, educação, saúde, transporte, etc.); o MPL perde seu protagonismo; a mídia concretiza a mudança discursiva da cobertura do movimento de negativa para positiva, dividindo os participantes em dois grupos: "manifestantes pacíficos" e "vândalos"; a repressão policial age para inibir as ações desse último grupo.

$\mathrm{Na}$ quarta fase, do dia 21 de junho em diante, embora haja protestos quase todos os dias em inúmeras cidades de norte a sul do país, eles perdem seu caráter nacional. As reivindicações são inúmeras, os jornais destacam os efeitos dos confrontos: número de feridos, presos, detidos. Outro foco da cobertura desse período são os anúncios das medidas tomadas pelos governos em reação aos protestos bem como uma discussão mais técnica sobre o transporte público. No mês de julho em diante, as pautas passam a ser motivadas por acontecimentos pontuais de cada cidade, como o desaparecimento e a morte do pedreiro Amarildo Dias de Souza, no Rio de Janeiro. Em algumas localidades há uma migração do formato "passeata" para o da "ocupação". Em todo esse período a repressão policial continua ativa. Traçada essa cronologia, é importante pensar como se deu, fase a fase, a mudança na configuração dos papeis dos atores sociais envolvidos nas manifestações.

\begin{tabular}{|c|c|c|c|c|}
\hline & Sofredor & Agressor & Observador & Audiência \\
\hline $\begin{array}{l}1^{\text {a }} \text { fase } \\
\text { Surgimento }\end{array}$ & $\begin{array}{l}\text { Sociedade Civil } \\
\text { Polícia }\end{array}$ & $\begin{array}{l}\text { Manifestantes do } \\
\text { MPL }\end{array}$ & $\begin{array}{l}\text { Imprensa tradicional } \\
\text { (destacada) }\end{array}$ & $\begin{array}{l}\text { Identificação com } \\
\text { o policial/herói e } \\
\text { com ela mesma } \\
\text { (sociedade civil) }\end{array}$ \\
\hline $\begin{array}{l}2^{\text {a }} \text { fase } \\
\text { Inflexão }\end{array}$ & $\begin{array}{l}\text { Manifestantes do } \\
\text { MPL } \\
\text { Sociedade Civil } \\
\text { Jornalistas }\end{array}$ & Polícia/Estado & $\begin{array}{l}\text { Imprensa tradicional } \\
\text { (não destacada) } \\
\text { Mídia social }\end{array}$ & $\begin{array}{l}\text { Identificação com } \\
\text { Os manifestantes } \\
\text { do MPL, com os } \\
\text { jornalistas agredidos } \\
\text { e com ela mesma } \\
\text { (sociedade civil) }\end{array}$ \\
\hline $\begin{array}{l}3^{\mathrm{a}} \text { e } 4^{\mathrm{a}} \text { fases } \\
\text { Ampliação e } \\
\text { Declínio }\end{array}$ & Sociedade Civil & $\begin{array}{l}\text { Estado } \\
\text { Governo do PT }\end{array}$ & $\begin{array}{l}\text { Imprensa tradicional } \\
\text { (não destacada) } \\
\text { Mídia social }\end{array}$ & $\begin{array}{l}\text { Identificação } \\
\text { com ela mesma } \\
\text { (sociedade civil) }\end{array}$ \\
\hline
\end{tabular}

Quadro 1. Caracterização midiática dos atores sociais das manifestações 
De início, os manifestantes ocupam o papel de vilão, pois são aqueles que lutam por uma pauta "injustificada", já que o aumento da passagem estava abaixo da inflação; atrapalham o direito de ir e vir da população, depredam o patrimônio público e usam de violência. A população é a vítima, pois sofre com ônibus queimados e fora de circulação, estabelecimentos depredados e a impossibilidade e/ou o medo de circular nas ruas. A polícia cumpre seu papel de braço armado do Estado e tem por função impedir a desordem, reprimir as manifestações e preservar o patrimônio, mesmo que para isso seja necessário usar a violência. Na segunda fase, em função da repressão policial, os manifestantes passam a ser identificados como vítimas, com a sociedade civil e a imprensa. A polícia por sua vez bate em todos e justo por isso assume o lugar de vilão ao lado de um Estado repressor que deixa/manda bater. Nas terceira e quarta fases, o vilão vai ficando cada vez mais caracterizado como um Estado que não oferece serviços públicos de qualidade à população para depois designar mais especificamente o governo do PT, que, ao desviar dinheiro público e cometer inumeráveis e gigantescos atos de corrupção, prejudica a todos.

Talvez alguns atores sociais com recursos financeiro e midiático tenham percebido que seria possível generalizar a posição de vítima da violência policial para a de vítima de políticos desonestos. Nesse sentido, diferentemente da tese de que a ampliação do movimento propiciou a abertura irrestrita da pauta, sustentamos um outro posicionamento: a entrada do tema específico "combate à corrupção" foi que permitiu a massificação das manifestações. O fato de a corrupção ter sido o único tópico de reivindicação que permaneceu como bandeira de luta nas manifestações de 2015 e 2016 endossa essa linha de argumentação.

\section{A cobertura midiática e as redes sociais}

Quando a tarifa de ônibus em São Paulo subiu de R\$ 3,00 para R\$ 3,20, o MPL convocou uma passeata contra o aumento. A estratégia era realizar, num curto intervalo de tempo, atos de impacto em vias mais centrais da cidade a fim de pressionar o poder público e fazer jus ao lema "Se a tarifa não baixar, a cidade vai parar!". Portanto, desde o início das manifestações, estava colocada a possibilidade de confronto com a aparição das figuras de vítima e vilão.

Na cobertura da primeira fase dos protestos, a mídia desqualifica sistematicamente o movimento, defendendo que a pauta era descabida porque o aumento estava abaixo da inflação e que as manifestações impediam o direito de ir e vir dos cidadãos. À proporção que os protestos iam ficando mais violentos, o argumento de dificultar a mobilidade das pessoas foi se transformando em incitação ao medo e ao caos. O MPL é definido como movimento radical que, apesar de se dizer apartidário, mantinha vínculos com partidos de esquerda. Os seus militantes são caracterizados como "vândalos" que "ateiam fogo, fazem barricadas, picham e depredam o patrimônio público". Contribui para a construção 
do perfil violento dos manifestantes as manchetes que acompanham as matérias em que aparecem as palavras "vandalismo", "destruição" e "caos".

O ato foi organizado pelo Movimento Passe Livre, que se diz apartidário. Mas contou com a participação de partidos políticos de esquerda e movimentos anarquistas. (FSP, 12/06/2013)

Novo ato contra a tarifa faz até colégio fechar mais cedo. Pelo segundo dia, grupo sai às ruas, picha ônibus, fecha vias e assusta comércio. (FSP, 8/06/2013) Manifestantes atearam fogo a pedaços de paus e fizeram barricadas na Avenida 23 de Maio em pleno horário de pico. Na Avenida Paulista, incendiaram uma cabine da Polícia Militar e picharam paradas de ônibus. (O GLOBO, 7/06/2013)
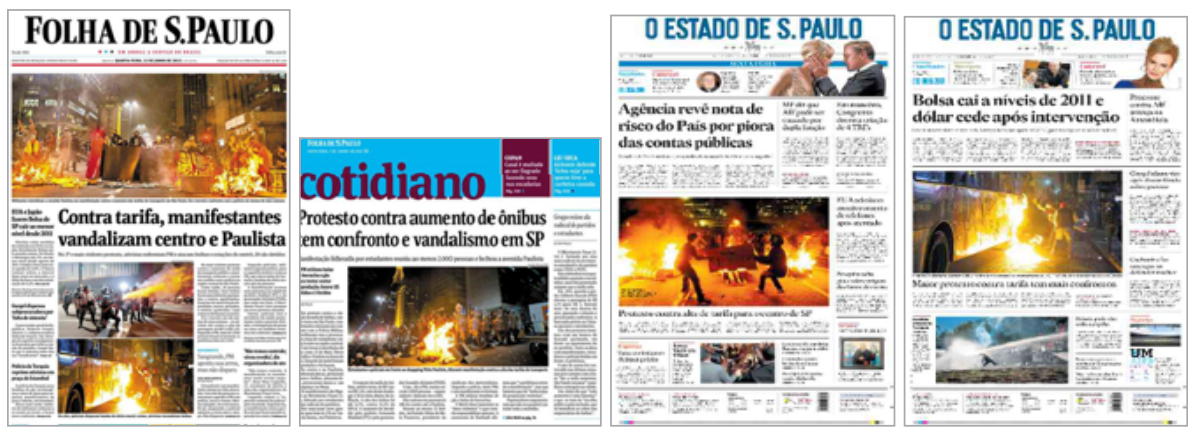

Fig. 1. Da esquerda para a direita: capa e contra capa da FSP de 12/06/2013; Capa de OESP de 07/06/2013 e de 12/06/2013

As fotografias põem em destaque estabelecimentos com fachadas apedrejadas, vidros quebrados, pessoas mascaradas, fogo, chamas, pneus e ônibus queimados, enfim, cenas de guerra, destruição e caos. Já os atos da polícia, mesmo os violentos, são retratados como mera reação ao "vandalismo" dos manifestantes. O policial é enaltecido como herói que arrisca a si próprio para proteger o patrimônio e a população.

Na quinta-feira, 13 de junho, enquanto os editoriais da FSP e do OESP pedem uma ação mais incisiva da polícia, o DataFolha mostra que $40 \%$ da população condenam a atuação da instituição. Sem dar ouvidos à pesquisa e atendendo ao pedido dos jornais, a polícia age de forma muito violenta nos protestos de quinta. Nesse momento, as pessoas se mostram muito indignadas com a brutalidade da polícia e passam a se posicionar na internet a favor do direito que todos têm de se manifestar na rua sem sofrer agressões. Assim, antes antipatizado por parte da população, o movimento ganha legitimidade popular, se viraliza e se nacionaliza.

Diante da truculenta ação da polícia e do apoio nas redes ao movimento, a imprensa muda de abordagem. O MPL, antes acusado pela FSP de vandalismo e de ser uma espécie de pau mandado do PSTU (Partido Socialista dos Trabalhadores Unificado) e do PSOL (Partido Socialismo e Liberdade), começa a aparecer nas matérias do jornal como 
"apartidário, sincero e não-violento". A polícia passa a ser referida como uma entidade "brutal", "violenta". No editorial de 15 de junho, a FSP deixa claro que as vítimas da ação policial não são apenas os manifestantes, mas as pessoas comuns.

No quarto protesto, a responsável maior pela violência passou a ser a própria PM. Pessoas sem envolvimento no confronto foram vítimas da brutalidade policial. Transeuntes, funcionários do comércio, manifestantes pacíficos e até frequentadores de bar foram atacados com cassetetes e bombas. Sete repórteres da Folha terminaram atingidos, quatro deles com balas de borracha, em meio à violência indiscriminada da polícia. (Editorial, FSP, 15/06/2013)

Já na edição de 14 de junho, a FSP destaca a imagem de um policial negro com um cassetete em punho espancando uma jovem que cai por cima de um rapaz na calçada. Aparentemente o casal está afastado do tumulto das manifestações, o que leva a supor a gratuidade da violência policial. Na capa aparece também a imagem de uma mulher com o olho direito sangrando. Trata-se da jornalista da Folha, Giuliana Valone, atingida por uma bala de borracha quando cobria a manifestação do dia anterior. No corpo das matérias, várias fotografias de pessoas feridas são perfiladas uma ao lado da outra dando a entender que a violência policial é uma prática generalizada que atinge a todos: manifestantes, jornalistas e pessoas comuns. Essa ampliação da noção de vítima de manifestantes para a população em geral revela como os papeis dos atores sociais envolvidos foram se transformando.

\section{FOLHA DE S.PAULO}
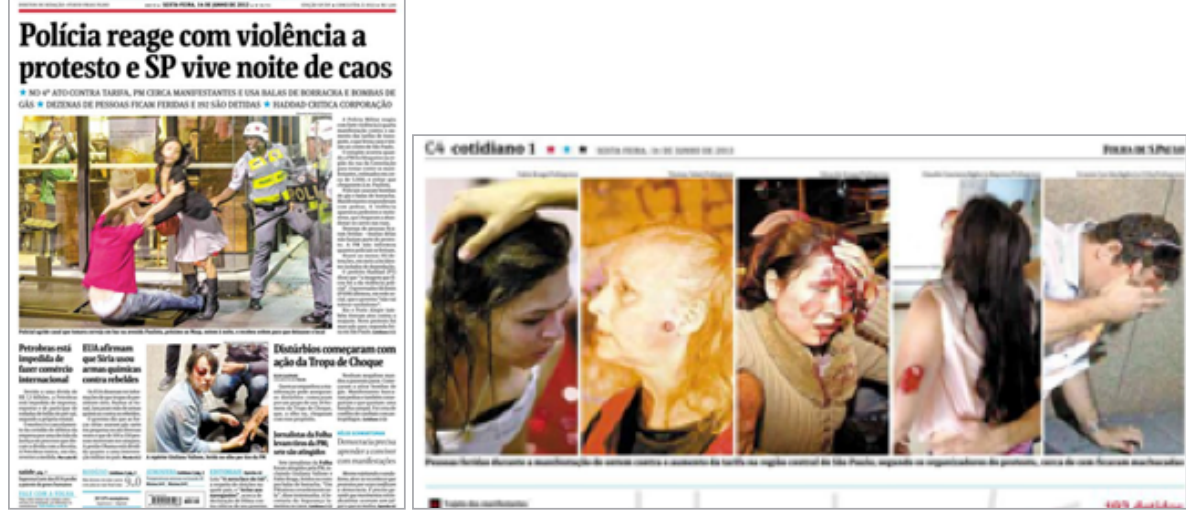

Fig. 2. Capa e ilustração de página interna do caderno Cotidiano da FSP de 14/06/2013

Vale registrar que ainda na quinta-feira, 13 de junho, o MPL divulgou o slogan "Não é por 20 centavos, é por direitos", na intenção de frisar que se tratava de uma luta mais ampla por um transporte público de qualidade. O slogan foi lido como ampliação da lista de reivindicações para outras áreas. Por exemplo, o site Protestaí disseminou uma 
publicação que se tornou a terceira mais compartilhada da quinta-feira e, na sexta-feira, assumiu o topo de compartilhamento no Facebook: "Não são 20 centavos, é uma geração acordando e exigindo melhorias! Hoje é transporte público, amanhã saúde e educação...". Na sexta, a segunda publicação mais compartilhada trazia a imagem de um manifestante com o rosto coberto segurando o seguinte cartaz: "Copa FIFA = 33 bilhõe $\$$, Olimpíada = 26 bilhõe $\$$, Corrupção = 50 bilhõe $\$$, Salário Min. = 678 reai \$, e você ainda acha que é por 20 centavos???". Aqui sugere-se a correlação entre o baixo salário da população e o alto custo das obras públicas, em especial pelo percentual de dinheiro destinado à corrupção.

A quinta publicação mais compartilhada da sexta-feira era uma imagem supostamente difundida pelo Anonymous Brasil de manifestantes com uma faixa dizendo: "O povo acordou, o povo decidiu, ou para a roubalheira, ou paramos o Brasil!". Esse enunciado deixa de lado todas as outras reivindicações para se centrar unicamente na questão da corrupção. É de se estranhar que um grupo anarquista surja na defesa da moralidade. Mas, como se verá adiante, esta não será a única manifestação atribuída ao Anonymous contra a corrupção. Hoje, no seu site, o grupo diz almejar "um mundo onde a corrupção não exista".

Impossível assegurar se surfando nessa onda da internet ou provocando-a, no curto intervalo de um final de semana, a mídia passou da constatação da violência policial à luta contra a corrupção. Na edição do sábado, 15 de junho, a Veja estampa a seguinte chamada: "A revolta dos jovens - depois do preço das passagens, a vez da corrupção e da criminalidade? A razão de tanta fúria - os jovens já marcharam pela paz, democracia e liberdade. Os de agora vão às ruas para baixar o preço das passagens. Mas isso é tudo?". Já a Revista de Domingo da Folha de 16 de junho traz a imagem de um cartaz onde se lê: "Isso é + do que um protesto contra o aumento/isso é um grito popular de que não aguentamos mais tanta corrupção." Nessa mesma edição circula a fotografia de um manifestante todo de preto pichando um muro e nas costas de seu casaco se vê um X riscado por cima da estrela do PT.
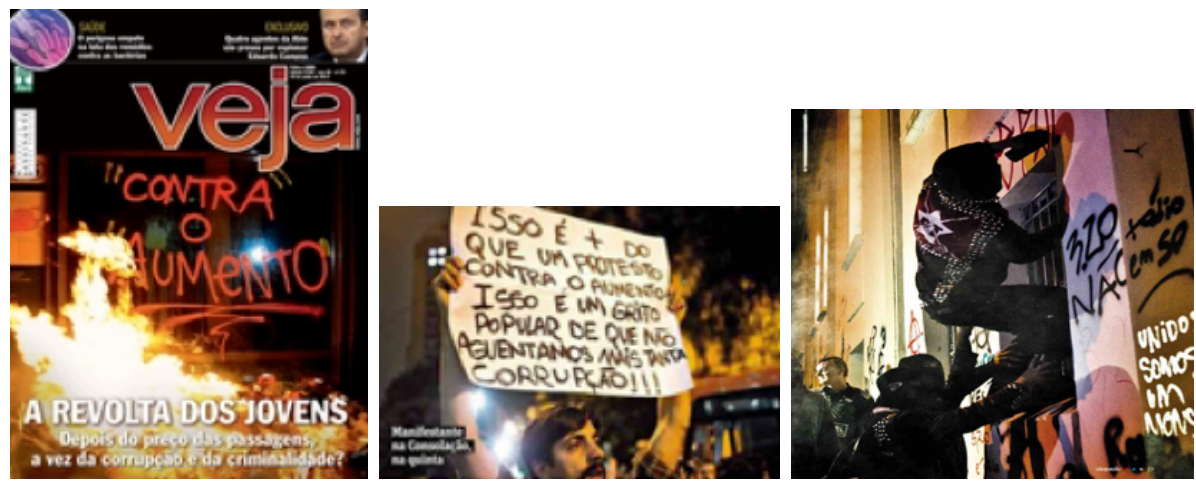

Fig. 3. Da esquerda para a direita: capa da Veja de 15/06/2013, fotografias veiculadas na edição de 16/06/2013 da Revista de Domingo da FSP.

Na manhã da segunda-feira, 17 de junho, Arnaldo Jabor faz uma autocrítica na rádio $\mathrm{CBN}$ (repetida à noite na sua coluna do Jornal Nacional), declarando-se a favor 
do movimento. Antes ele havia dito que os manifestantes eram revoltosos de classe média que não sabiam por que estavam na rua protestando e não valiam nem 20 centavos, agora ele assume que julgou mal as manifestações conduzidas pelo MPL e considera positivo o fato de o movimento "não ter rumo e objetivo certo". Nesse sentido sugere que o MPL encabece outras pautas, como a luta contra a corrupção, materializada mais especificamente na oposição à PEC 37, tema no qual a Globo insistirá.

Na terça-feira, 18 de junho, começa a circular na internet um outro vídeo atribuído ao grupo Anonymous Brasil, nomeado "As cinco causas", no qual o tema do combate à corrupção e à PEC 37 é o mote principal. No dia19 de junho, a tarifa baixa em São Paulo, mas essa conquista não impede que novas megamanifestações ocorram no dia seguinte. Na quinta-feira, 20 de junho, os protestos atingem 300 cidades e colocam 1 milhão de pessoas nas ruas. Nessa data, a Rede Globo deixa de exibir suas novelas para cobrir os protestos por todo o país. Em Brasília são 25 mil pessoas na Esplanada, no Rio de Janeiro 300 mil pessoas vão às ruas e há confronto violento com a polícia. Em São Paulo, as vias públicas são tomadas por 100 mil pessoas. Não há confronto dos paulistanos com a polícia, mas entre manifestantes "apartidários" e aqueles com bandeira ou camisa de partidos. Bandeiras do PT são queimadas. Afirmando-se "apartidário", mas não "antipartidário", o MPL acusa o fascismo subjacente a tais agressões e anuncia a saída dos protestos.

Após a megamanifestação do dia 20 e até o final do mês de junho, os protestos continuam, especialmente no entorno dos estádios da Copa das Confederações. Muitas manifestações migram para o formato da "ocupação" de assembleias, câmaras, palácios e outros espaços públicos. A partir de julho, as manifestações vão se espaçando, se arrefecendo e perdendo seu caráter nacional. Permanecem mais fortemente apenas no estado do Rio, que registra protestos em série durante todo o $2^{\circ}$ semestre de 2013.

Como efeito dos protestos, no dia 24 de junho, a ex-presidente Dilma propõe um plebiscito para uma Constituinte exclusiva visando à reforma política e também a uma lei que tornasse a corrupção crime hediondo. A primeira proposta não vinga, mas no dia 26 de junho, o Senado aprova em votação simbólica a lei que tornou hediondo os crimes de corrupção. No dia anterior, 25 de junho, após uma campanha acirrada do Ministério Público com apoio da mídia, a PEC 37 foi derrubada no Congresso Nacional por 430 votos a nove. Tudo isso mostra como foi se instalando o cenário de grande apelo popular de combate à corrupção no país.

No dia 29 de junho, o Datafolha divulga uma pesquisa mostrando que, após a onda de protestos, a popularidade da ex-presidente Dilma tinha despencado $27 \%$. Três semanas antes, quando o país ainda não era palco das manifestações, seu índice de aprovação era de 57\%. Daí por diante, o índice de aprovação do governo só caiu. E nas manifestações de 2015 e 2016 não se gritava mais pela redução de passagem, tarifa zero, serviços públicos de qualidade. Só se falava em derrubar o "governo corrupto do PT". 
Com esse panorama mostramos a relevância da violência policial para generalizar a condição de vítima e, assim, abrir espaço para cidadãos como vítimas de imorais (do PT). Também apontamos a importância do intervalo entre 13 e 17 de junho, no sentido de uma ação surpreendentemente consensual de parte da mídia hegemônica e também de grupos com respaldo na rede, como os vídeos do Anonymous dos dias 17 e 19 de junho, para introduzir a corrupção na pauta.

\section{Considerações finais}

Sem que isto estivesse posto em sua origem e afastando-se da dimensão libertária das primeiras manifestações, as jornadas de junho de 2013 tornaram-se a semente dos protestos de 2015 e 2016 contra o governo da ex-presidente Dilma Rousseff que culminaram no seu impeachment. O elemento decisivo de construção da continuidade entre as jornadas e o golpe foi, inicialmente, a entrada da corrupção na pauta de reivindicações das manifestações de 2013 e, posteriormente, o lugar central que ela passou a ocupar na crítica ao funcionamento da política brasileira, em particular após a Lava Jato.

Mas não foi só isso. Até 2012, predominavam em território nacional os sentimentos de orgulho e confiança no futuro. Naquela época o Brasil parecia estar no limiar do hall dos países desenvolvidos. A economia crescia e a desigualdade diminuía. Para completar o clima de festa, o país sediaria a Copa do Mundo de 2014 e as Olimpíadas de 2016. As jornadas de 2013 marcam também o início de uma drástica mudança de sentimento do brasileiro para consigo mesmo e o país. Três emblemáticas capas da revista britânica The Economist ilustram a inflexão que o Brasil sofreu depois de 2013 e os rumos que a política tomou a partir daí.
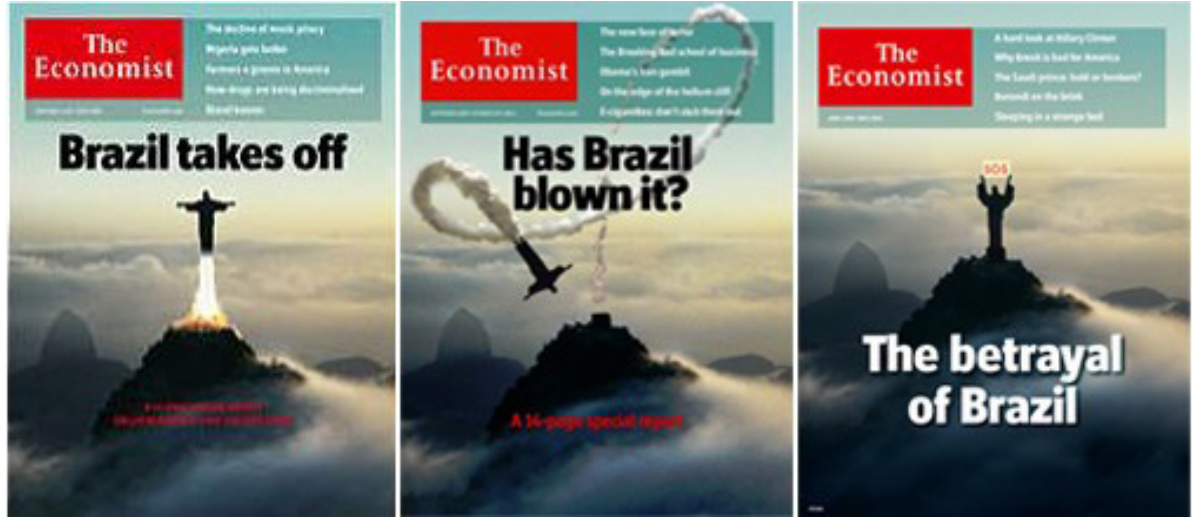

Fig. 4. Da esquerda para direita: edições de 11/2009, 10/2013 e 04/2016 da revista The Economist.

Em novembro de 2009 a publicação chamou o Brasil de "a maior história de sucesso na América Latina". Na capa, o Cristo Redentor aparece decolando como se fosse 
um foguete junto à manchete "Brasil decola". Apenas quatros anos depois, em outubro de 2013, o Cristo Redentor afunda após um voo, e a revista questiona: "Será que o Brasil estragou tudo?". Tomando os protestos de junho como marco, The Economist se perguntava se a presidente Dilma Rousseff iria conseguir "recolocar o país nos eixos em meio a uma economia estagnada e um Estado inchado". À época, a revista sentenciou: "Muitos agora perderam a esperança de que seu país estava fadado ao sucesso e concluíram que foi apenas outro voo de galinha". Vale frisar que, quando a segunda capa foi lançada, ainda não existia crise econômica (o PIB do Brasil cresceu 3\% em 2013) - e mesmo agora ela não explica por si só o grau de negatividade da população para com o país. A terceira capa circulou após a votação do impeachment de Dilma na Câmara dos Deputados, em abril de 2016. Dessa vez o Cristo Redentor aparece segurando uma placa de "S.O.S" ao lado dos dizeres "A traição do Brasil". A revista insinua que Dilma e os políticos haviam traído a nação, mas se mostra esperançosa com a Lava Jato, fruto da "maturidade do país e de uma nova e bem-educada classe média, que se nega a se envolver com a impunidade". O texto sugere que apenas novos legisladores poderiam realizar as reformas necessárias ao Brasil, pois todo o Congresso estaria "infestado de corrupção". Como se vê, a aliança entre neoliberalismo e combate à corrupção não foi contingente.

As críticas do MPL ao Estado por gastar na Copa e não nos transportes, beneficiando um grupo em detrimento de outro, foram apropriadas e ressignificadas conservadoramente. Assim, as jornadas sedimentaram o solo para instauração da característica definidora da política na atualidade: a corrupção dos "políticos". Desde então, especialmente com a Operação Lava Jato, o movimento anticorrupção só se fortalece. Mídia, sociedade civil, Ministério Público, Justiça e Polícia Federal, lançaram-se numa caçada à classe política - e, claro, o PT se singularizaria pelo grau de corrupção. A crítica política não tem mais como objeto os interesses que governos e representantes atendem, reduziu-se à repugnância alimentada midiaticamente sobre sua imoralidade. Destino curioso para as jornadas, um movimento que trouxe a muitos a esperança de reanimar a política.

Cristina Teixeira Vieira de Melo é professora do Departamento e Programa de Pós Graduação em Comunicação Social da UFPE.

cristinateixeiravm@gmail.com

Paulo Roberto Givaldi Vaz é professor da ECO-UFRJ.

paulovaz.ufrj@gmail.com 


\section{Referências}

AVRITZER, L. Impasses da democracia no Brasil. Rio de Janeiro: Civilização Brasileira, 2016.

BARROSO, L. R. A judicialização da vida e o papel do Supremo Tribunal Federal. Belo Horizonte: Fórum, 2018.

GODOY, F. (Orga.). O Brasil nas ruas. Rio de Janeiro: Globo, 2013. Disponível em: <URL do e-book aqui>. Acesso em: 15 Ago. 2017.

JUDENSNAIDER, E. et al. A luta contra o aumento. São Paulo: Editora Veneta, 2013.

KRASTEV, I. Shifting Obsessions: three essays on the politics of anticorruption. Budapest: Central European University Press, 2003.

ROSANVALLON, P. La contre-démocratie: la politique à l'âge de la défiance. Paris: Éditions de Seuil, 2006.

SOUZA, J. A radiografia do golpe: entenda como e por que você foi enganado. Rio de Janeiro: Leya, 2016.

SOUZA, L.; LARMOUR, P. e HINDESS, B. (orgs.). Government, NGOs and Anti-Corruption: the new integrity warriors. Oxford: Routledge, 2009.

Artigo recebido em 08/10/2017

e aprovado em 20/05/2018. 